\title{
LINEAR FRICTION WELDING - PROCESS CONTROL AND MACHINE TECHNOLOGY
}

\author{
N.PIOLLE ${ }^{1}$ \\ ${ }^{1}$ ACB - 27 rue du Ranzai, 44319 Nantes, France
}

\begin{abstract}
$\underline{\text { Abstract }}$
Linear Friction Welding (LFW) is well adapted to produce titanium aircraft engine and structure parts, as an alternative to machining from solid, from forging or from electron beam welded blanks. The process can be described through a small number of mechanical variables: the amplitude and frequency of oscillation motion, the contact pressure and the axial displacement resulting of hot material flowing outside of the joint interface. Nonetheless, because of the high speeds and loads, the correct control and monitoring of linear friction welding requires special care on machine and tooling design.
\end{abstract}

The main principles of LFW machine design are described, with a special focus on the consistency between process quality requirements and machine characteristics: the static and dynamic machine behavior, the control system performance, the sensor technology and the tooling clamping solutions shall allow a good control of the weld parameters and an accurate monitoring of the physical phenomena at the joint interface.

\section{Introduction}

Linear Friction Welding (LFW) is a solid-state joining process as it does not cause melting of the parent material. It produces forge quality, high integrity joints, with narrow heat affected zone. Materials are forged using frictional heat through the controlled, reciprocal linear oscillation movement of two components under high contact load. As the faying surfaces rub together, the material at the interface is heated to a plastic state, while axial load is maintained. The layer of soften material is expelled out of the interface, as flash, under the combined action of the contact pressure and the oscillation motion pushing out a small amount of material at each oscillation. The oscillation motion is stopped after a desired parameter has been reached: axial shortening, absolute position, time, or a combination of these three. The two components are then aligned, and the axial load is maintained or increased to consolidate the joint. The process is controlled by a small number of input parameters: the oscillation amplitude, the oscillation frequency, the axial pressure, and the end criterion for the oscillation motion. The main outputs, or process resulting parameters, are the in-plane friction force, the temperature increase at the interface, and the material flow resulting in upset displacement and flash. The process gives remarkably good results on titanium alloys thanks to their low thermal conductivity and consequently an ability to plasticize closely to the faying surface. In the late 1990's, LFW was investigated by Vairis and Frost $[1,2]$ and they made a description of the process in four steps: the initial phase, the transition phase, the equilibrium phase and the deceleration phase. Their investigations were the starting point of many 
works and influenced the way research and industrial people investigated LFW and developed numerical modeling approaches. Temperature profile in LFW of Ti-6Al-4V was rapidly well understood and many observations showed that welding temperature is just beyond beta transus temperature. We had to wait for Turner et al. [3] works using FEM analysis to have a better idea of strain rates. The works of Wanjara and Jahazi [4] shall be mentioned for understanding the impact of process parameters for alpha-beta Ti-6Al-4V welding. They demonstrated that LFW process window resulting in sound welds is very wide. Additional conclusions regarding process parameters optimization were given by Romero et al. [5], they demonstrated that residual stress would be advantageously mitigated using high pressure in LFW.

LFW of Ti-6Al-4V is now well understood by scientific community and process parameters providing sound welds seem to be well defined. Particularly process conditions consisting of amplitude between $2 \mathrm{~mm}$ and 2.5 $\mathrm{mm}$, a frequency between $35 \mathrm{~Hz}$ and $50 \mathrm{~Hz}$ and a minimum upset distance of $2 \mathrm{~mm}$ are making consensus. Impact of weld pressure is not as evident because no affection was found on elongation or mechanical resistance using whether $50 \mathrm{MPa}$ or $90 \mathrm{MPa}$. However, this parameter was found to have a significant impact on residual stress and literature suggests that high pressures should be preferred as it reduces the heat input: indeed, a higher pressure causes the material to flow at a lower temperature, and the faster upset speed leads to shorter heating time. Except the small impact on elongation at low amplitude or frequency, authors agree that there is a very wide process window, within which welds properties match base material properties.

\section{Design principles of a Linear Friction Welder}

\section{II.a. Mechanical design}

The mechanical design of a linear friction welder generally consists of a main frame, an oscillation actuator and slide, a forge actuator and slide, a fixture for the oscillating part and a fixture for the non-oscillating parts. One major technical challenge of such machine is to achieve a good dynamic control and monitoring of the relative motion and loads between the two weld parts, despite the high level of vibrations created by the alternating friction force at the interface and the inertia loads of oscillation slide. The required characteristics for enabling an acceptable process control quality are: a very stiff mechanical structure with good vibration dampening system, a powerful and friction-less oscillation actuator, heavy duty slide bearings, a direct measurement of displacement and loads, a fast data acquisition system, a fast control loop, and very rigid fixtures including a high force clamping system. 

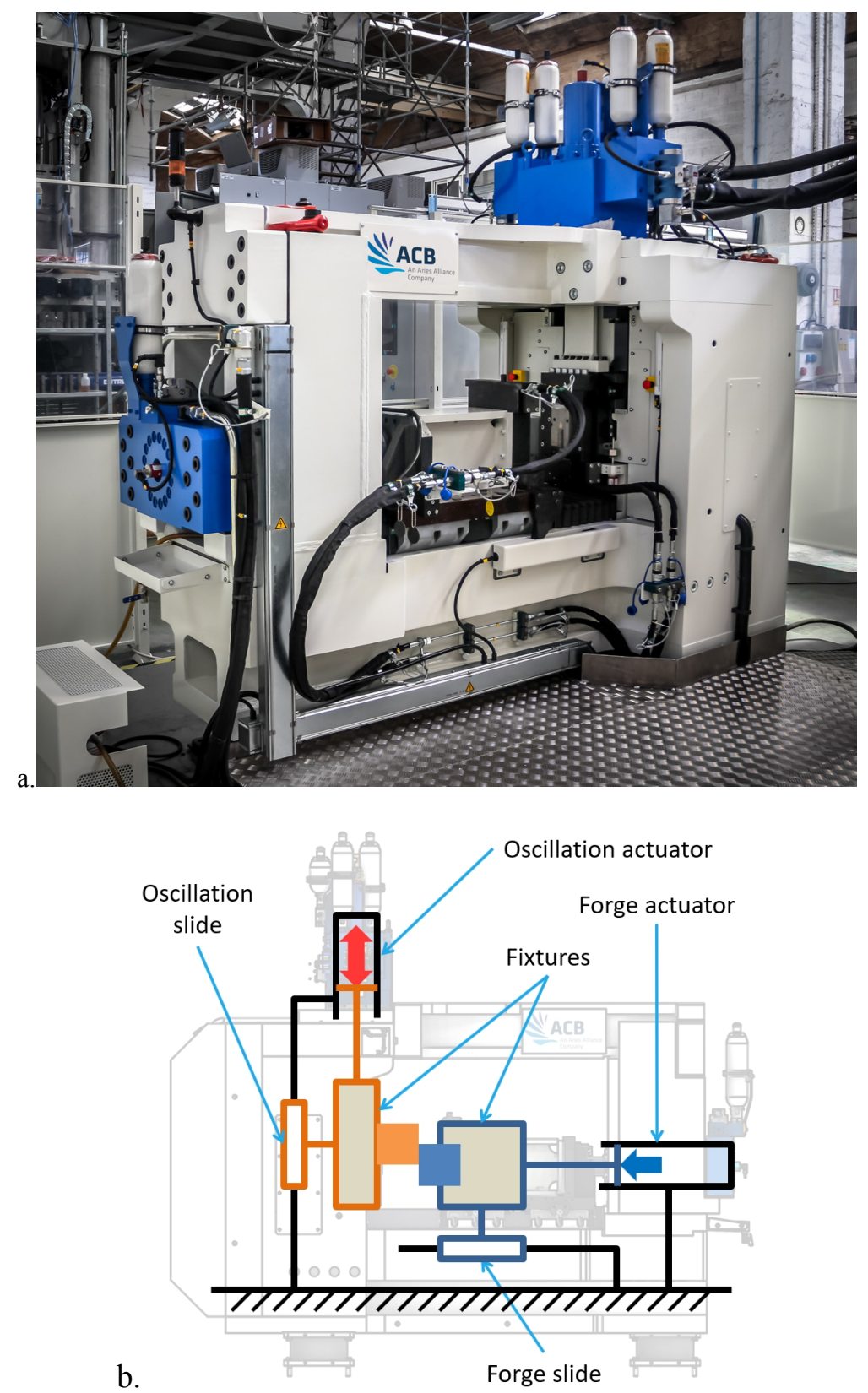

Figure 1: Linear Friction Welder picture (a) and main features (b)

II.b. Control of the axes 
The oscillation actuator is closed-loop controlled in position during the friction phase. This position control is based on position sensors on the oscillation slide. In addition to position sensors, the oscillation axis is equipped with load sensors that provide some information for the calculation of in-plane friction load at the interface and weld power input.

The forge actuator is closed-loop controlled in load during the friction phase and forge phase. This load control is based on load sensors in the connecting elements between actuator and carriage, and inside the actuator itself. In addition to load sensors, the forge slide is equipped with position sensors that are used to monitor the upset displacement during the friction phase.

\section{II.b. In-process quality control (IPQC)}

The LFW machines can include an In-Process Quality Control (IPQC). The data measured during the welding are compiled into a weld signature, which is automatically compared to a reference signature in order to assess whether the weld is within a predefined acceptable process window, or not. The IPQC involves static limits, dynamic limits and statistical limits. This tool provides further information about deviations on machine behavior or tooling behavior by analyzing a population of welds, for example a whole production batch. A weld report is automatically generated at the end of the weld, as well as a production batch report at the end of the batch. The Figure 2 shows the basic principles of IPQC.

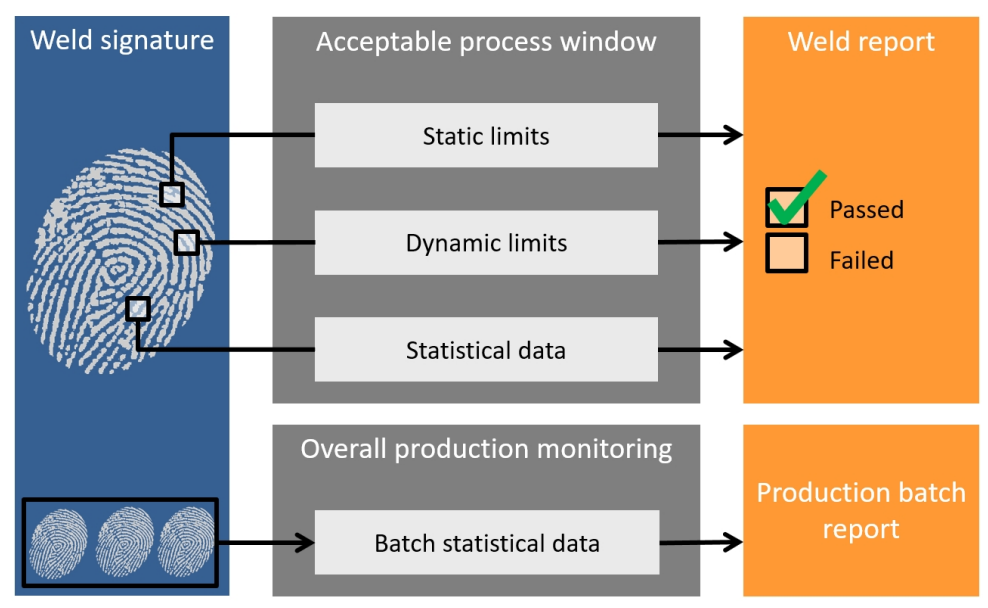

Figure 2. In-process quality control principle.

\section{Process control accuracy}

The execution of LFW process involves a fairly low number of input parameters, mainly loads and displacements, to the extent that it can be fully automated. With the developments of the technology on servohydraulic systems, sensors and high-speed acquisition systems, modern hydraulic LFW machines are able to 
achieve very accurate and repeatable process control, provided the machine mechanical structure is stiff enough and with the use of rapid and smart motion control algorithms.

In production, as the process is fully automated, most of the process quality insurance could be based on inprocess measurements. The end user of LFW technology could be interested in any data about the process repeatability, and in particular the repeatability of power input. Experiments conducted with LFW coupons instrumented with thermocouples give some indications on the approximate temperature level near the weld zone. This method is interesting as it provides temperature direct measurement. Moreover, it is possible to place several thermocouples at different locations in the coupon, in order to extrapolate a temperature field in the part, and eventually calculate the heat input. This method with thermocouples provides much more interesting results than using high speed video camera, which can measure only the outer surface of the weld part, and only during the conditioning phase - before the flash obstructs the visual access to the weld interface. However this experimental protocol is most of the time impossible to implement in an industrial environment on production parts, and it involves several sources of inaccuracy: thermocouple reliability and accuracy, measurement difficulty in vibrating environment, high speed of thermal and mechanical phenomena, reliability of the method for gluing thermocouples in the coupons and extrapolation from discrete temperature measurements to power input.

Two methods have been proposed to get a better picture of process behavior and power input. One is based on the upset speed, the other is based on the power input by measuring the in-plane friction load. In both cases, the variables to be compared are output parameters. Beforehand, it is necessary to check that the input parameters, or process conditions, are correctly and consistently controlled. The following results come from investigation on the MDS30, a linear friction welder having a forge force of $300 \mathrm{kN}$, in operation at $\mathrm{ACB}$, Nantes, France.

A study of 6 tests performed in longitudinal oscillation and 6 others in transverse oscillation was conducted. These tests were done on Ti-6Al-4V coupons, in butt-welding configuration and faying surface was $80 \mathrm{~mm} \times$ $25 \mathrm{~mm}$. The following input parameters were used: amplitude displacement of $2 \mathrm{~mm}$, frequency of $50 \mathrm{~Hz}$, pressure of $90 \mathrm{MPa}$ and an upset of $3 \mathrm{~mm}$. The criterion for stopping the oscillation is the upset length, so the duration of friction is a result, an output value. 


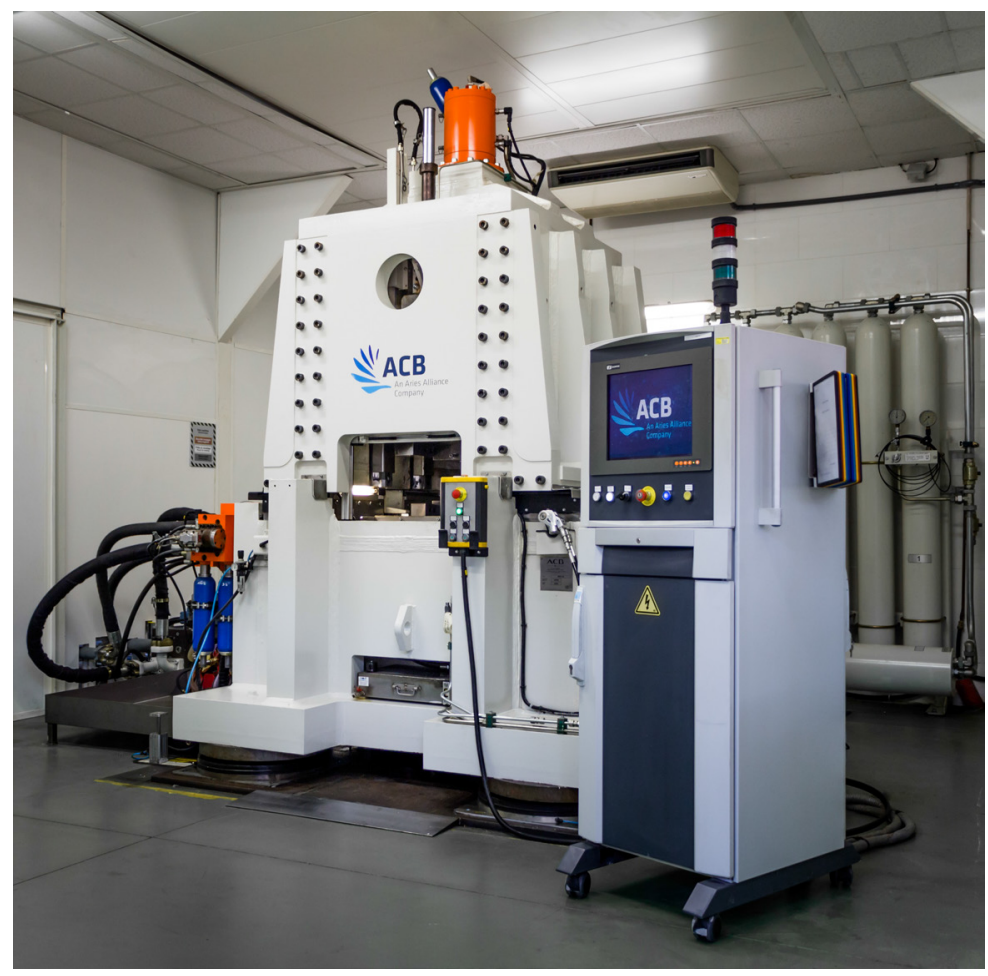

Figure 3: MDS30 Linear Friction Welder

\section{III.a. Accuracy of input parameters control}

Regarding the oscillation displacement, the machine sensors provide data on the position error, the amplitude error and the average amplitude error. The position error is the instantaneous difference between position command and position feedback. The amplitude error is the difference between peak amplitude command and peak amplitude feedback, measured on one period of oscillation. The average amplitude error is the difference between the amplitude setpoint and the average of all amplitude feedbacks, calculated on the whole steady state friction phase.

It is observed that the maximum instant error between command and response is below $0.3 \mathrm{~mm}$ during rampup and ramp-down, and below $0.1 \mathrm{~mm}$ ( $5 \%$ of nominal amplitude) during steady state. During steady state, the amplitude error is below $0.05 \mathrm{~mm}$ ( $2.5 \%$ of nominal amplitude), and the average amplitude error is below $0.015 \mathrm{~mm}(0.75 \%$ of nominal amplitude). Figure 4 is an illustration of these performances taken from a recording of one test sample. 


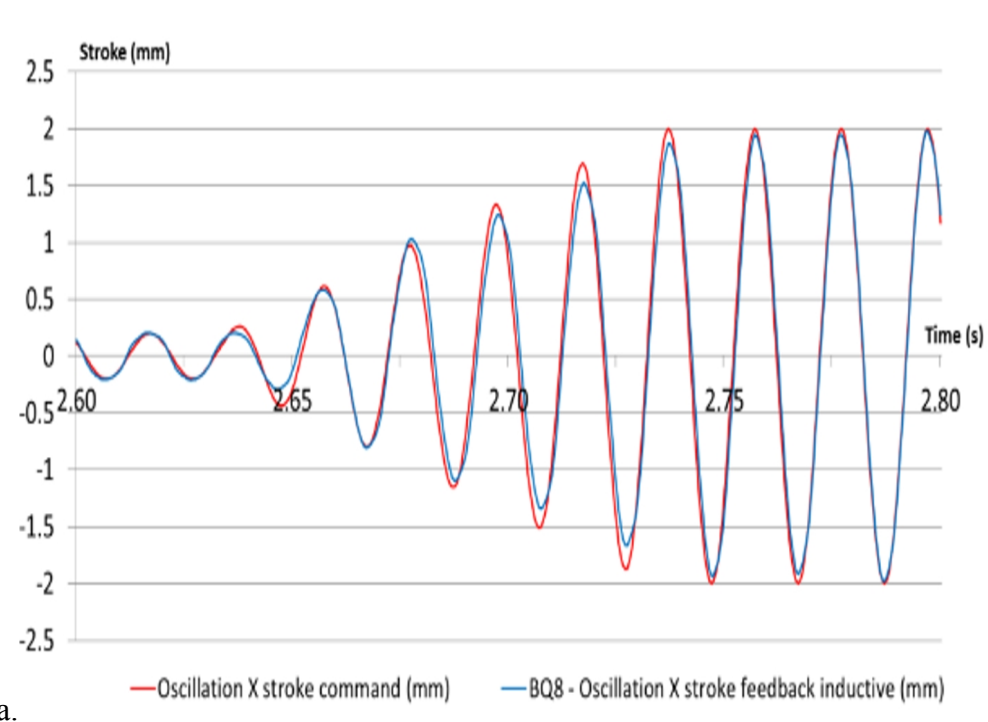

a.

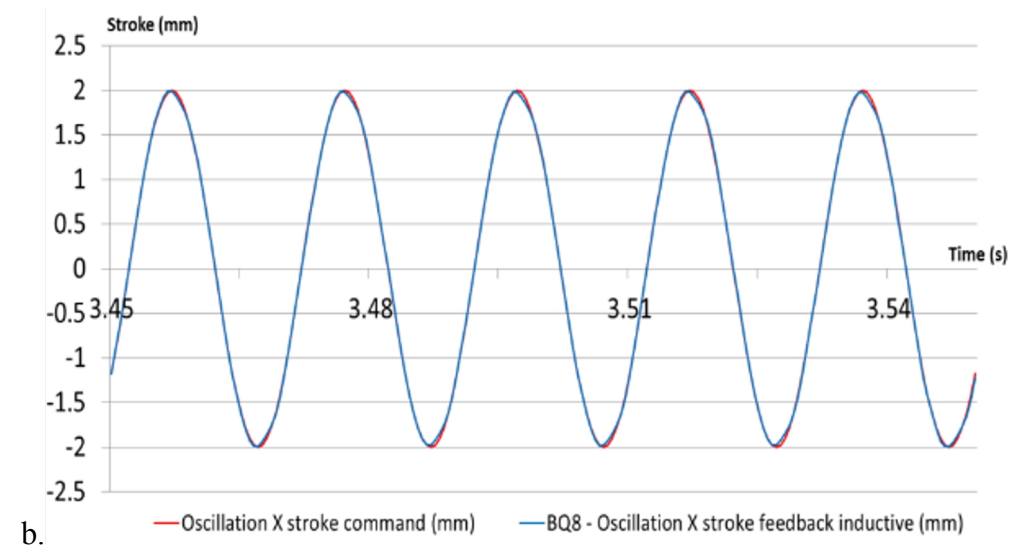

Figure 4. Comparison between oscillation command (in red) and oscillation feedback (in blue), a. during the rampup phase - b. during the steady-state phase.

Regarding the control of forge force during the steady state friction phase, the instantaneous error between command and feedback was found to be below $10 \mathrm{kN}$ (5.6\% of nominal forge), and the average forge force error was found to be below $0.5 \mathrm{kN}(0.28 \%$ of nominal forge force $)$.

These performances on the control of input parameters are far beyond expectations of Ti-6Al-4V weldability process window. This level of performance allows to make some valid deductions regarding the process repeatability, by analyzing output parameters like upset speed or in-plane friction loads.

III.b. Repeatability of upset speed 
The comparison of upset curves gives an information on the repeatability of process behavior. Figure 5 is a superposition of the upset displacement curves for six longitudinal welds performed in the exact same conditions.

The upset rates achieve a repeatable profile during each cycle. From one weld to another, some small variations can be observed in the duration of conditioning phase. The maximum dispersion on friction duration is found to be $\pm 30 \mathrm{~ms}$ for the six longitudinal welds, and $\pm 65 \mathrm{~ms}$ for the six transversal welds. The dispersion could be caused by small differences in surface finish, part preparation, and thermal phenomena at the edges. The superposition of upset speeds on Figure 6 highlights that the largest variations in upset displacement occur during transition phase, between conditioning and equilibrium.

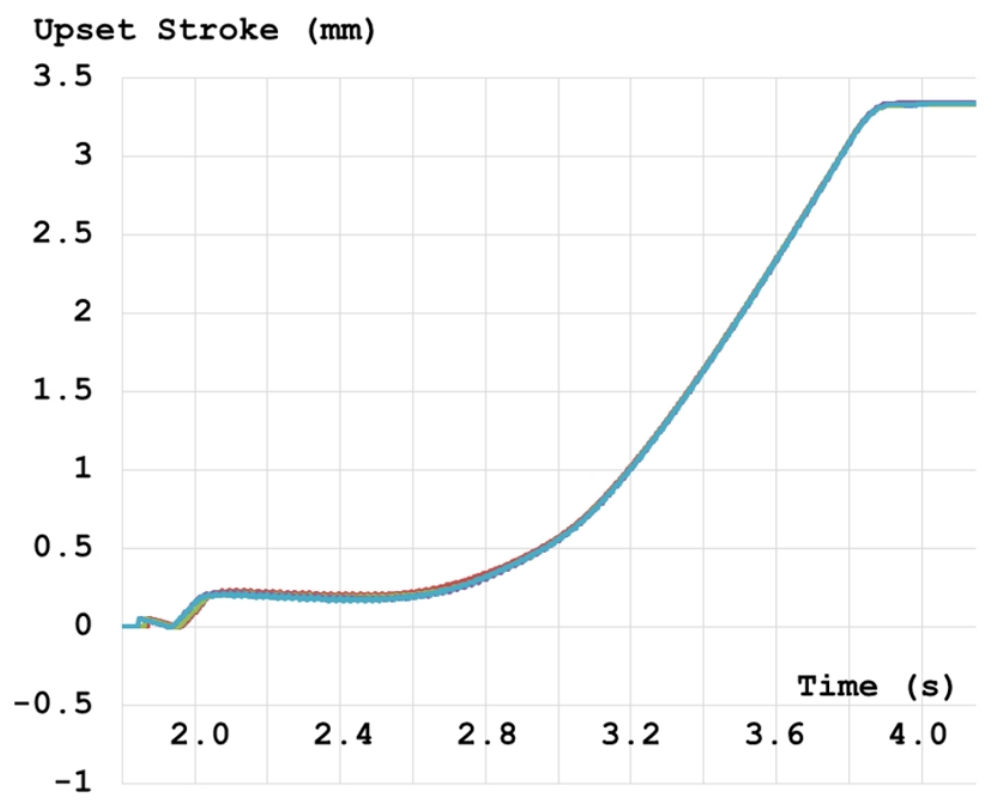

Figure 5. Superposition of six recordings of upset curves, longitudinal configuration. 


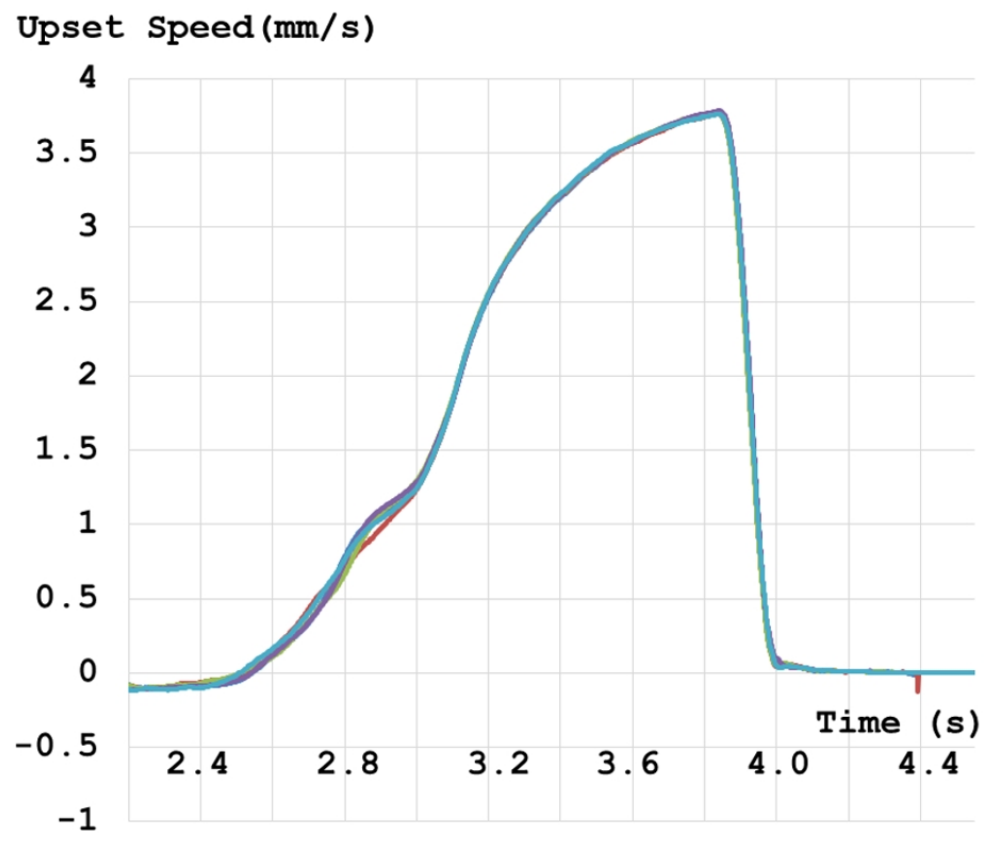

Figure 6. Superposition of six recordings of upset speed curves, longitudinal configuration.

\section{III.c. Repeatability of power input}

The power input can be measured, provided the machine is instrumented to accurately measure the in-plane friction loads. At any time, the instantaneous in-plane friction load is calculated using the oscillation actuator load, inertia loads, and friction forces in the oscillation guiding system, as per following equation:

$$
F_{\text {in-planefriction }}(t)=F_{\text {actuator }}(t)-F_{\text {inertia }}(t)-F_{\text {guiding }}(t)
$$

The oscillation actuator load $F_{\text {actuator }}(t)$ is measured directly in real time by load cell or hydraulic pressure sensors. The inertia load $F_{\text {inertia }}(t)$ is calculated in real time with the oscillation mass and the direct measurement of acceleration. The resistant load $F_{\text {guiding }}(t)$ in the guiding is evaluated during a systematic check test done on the machine before the weld, and directly taken into account in the calculation of in-plane friction load.

The power input is the result of the work of friction force and forge force. With the measurement of in-plane friction force, oscillation displacement, forge force and upset displacement, it is possible to estimate the specific energy input: 


$$
E_{s}=\frac{1}{S} \int_{t_{1}}^{t_{2}}\left(F_{x}(t) \cdot V_{x}(t)+F_{z}(t) \cdot V_{z}(t)\right) \cdot d t
$$

With:

- $E_{S}$ : specific energy supplied to weld interface, from the time $t_{1}$ to the time $t_{2}\left(\mathrm{~J} / \mathrm{m}^{2}\right)$

- S: surface of weld area $\left(\mathrm{m}^{2}\right)$

- $F_{X}(t)$ : in-plane friction force at the time $t,(N)$

- $\mathrm{V}_{\mathrm{x}}(\mathrm{t})$ : oscillation speed at the time $\mathrm{t},(\mathrm{m} / \mathrm{s})$

- $F_{z}(t)$ : forge force at the time $t,(N)$

And at any time $t_{i}$, the average specific power input on one period of oscillation:

$$
P_{s}=\frac{1}{S . T} \int_{t_{i}}^{t_{i}+T}\left(F_{x}(t) \cdot V_{x}(t)+F_{z}(t) \cdot V_{z}(t)\right) \cdot d t
$$

With:

- $\mathrm{P}_{\mathrm{s}}$ : specific power input on the period $\mathrm{T}\left(\mathrm{W} / \mathrm{m}^{2}\right)$

- $\mathrm{T}$ : period (s),

The Figure 7 compares the contributions of in-plane friction force and forge force to the power input. The contribution of forge force to power input is very low compared to the contribution of friction force. This is explained by a very low upset speed compared to oscillation speed, with a friction force higher than the half of forge force. According to LFW machine acquisitions, for the longitudinal welds, the overall specific energy provided by the work of friction force is about $32 \mathrm{~J} / \mathrm{mm}^{2}$, whereas the energy provided by the work of forge force is only $0.3 \mathrm{~J} / \mathrm{mm}^{2}$.

The Table 1 gives the specific energy and specific power generated by the friction force, as well as friction duration, for longitudinal welds and transversal welds. For each weld configuration, the energy, power and friction time are the average values for the six welds, longitudinal or transversal. The "maximum variation" is the maximum difference between two individual values, expressed in percentage of the average value.

The Figure 8 shows the evolution of in-plane friction coefficient and upset displacement. The in-plane friction factor is the ratio between peak in-plane force and forge force, for each period of oscillation. 


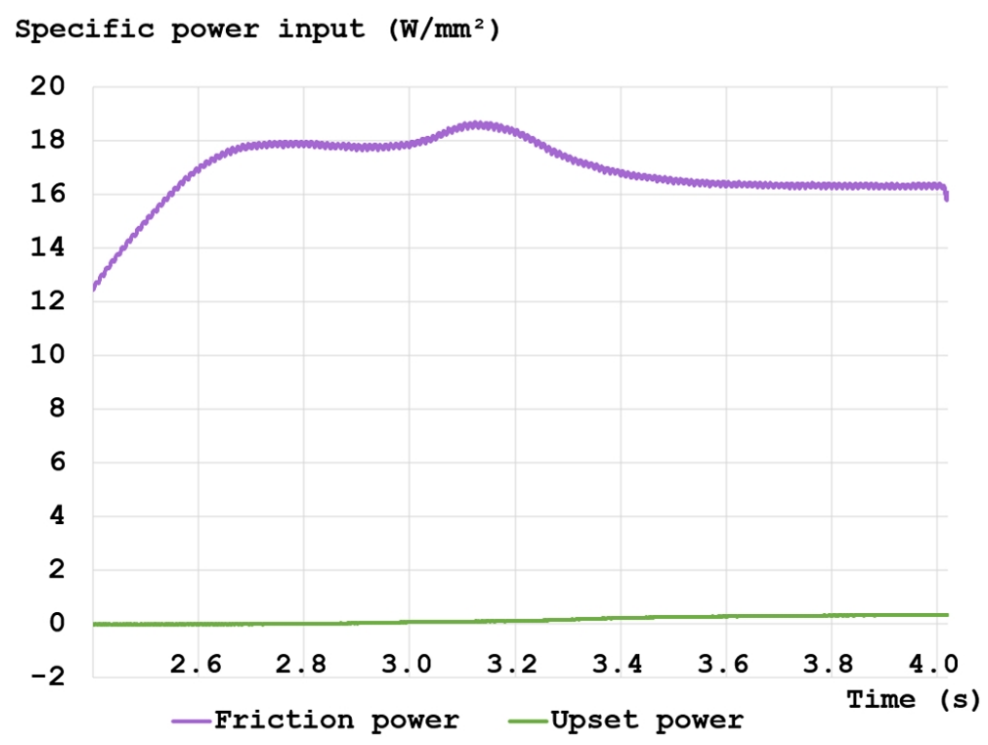

Figure 7. Specific power input, generated by the work of friction force and forge force, for a longitudinal weld.

\begin{tabular}{|l|l|l|}
\cline { 2 - 3 } \multicolumn{1}{c|}{} & Longitudinal welds & Transversal welds \\
\hline Total specific energy input $\left(\mathrm{J} / \mathrm{mm}^{2}\right)$ & 31.62 & 24.74 \\
\hline Maximum variation & $\pm 0.59 \%$ & $\pm 2.39 \%$ \\
\hline Specific power input during burn-off $\left(\mathrm{W} / \mathrm{mm}^{2}\right)$ & 16.85 & 19.57 \\
\hline Maximum variation & $\pm 0.62 \%$ & $\pm 2.35 \%$ \\
\hline Friction duration $(\mathrm{s})$ & 1.858 & 1.273 \\
\hline Maximum variation in friction duration & $\pm 0.74 \%$ & $\pm 4.95 \%$ \\
\hline
\end{tabular}

Table 1. Specific energy, specific power and friction duration for longitudinal welds and transversal welds, measured by LFW machine. 


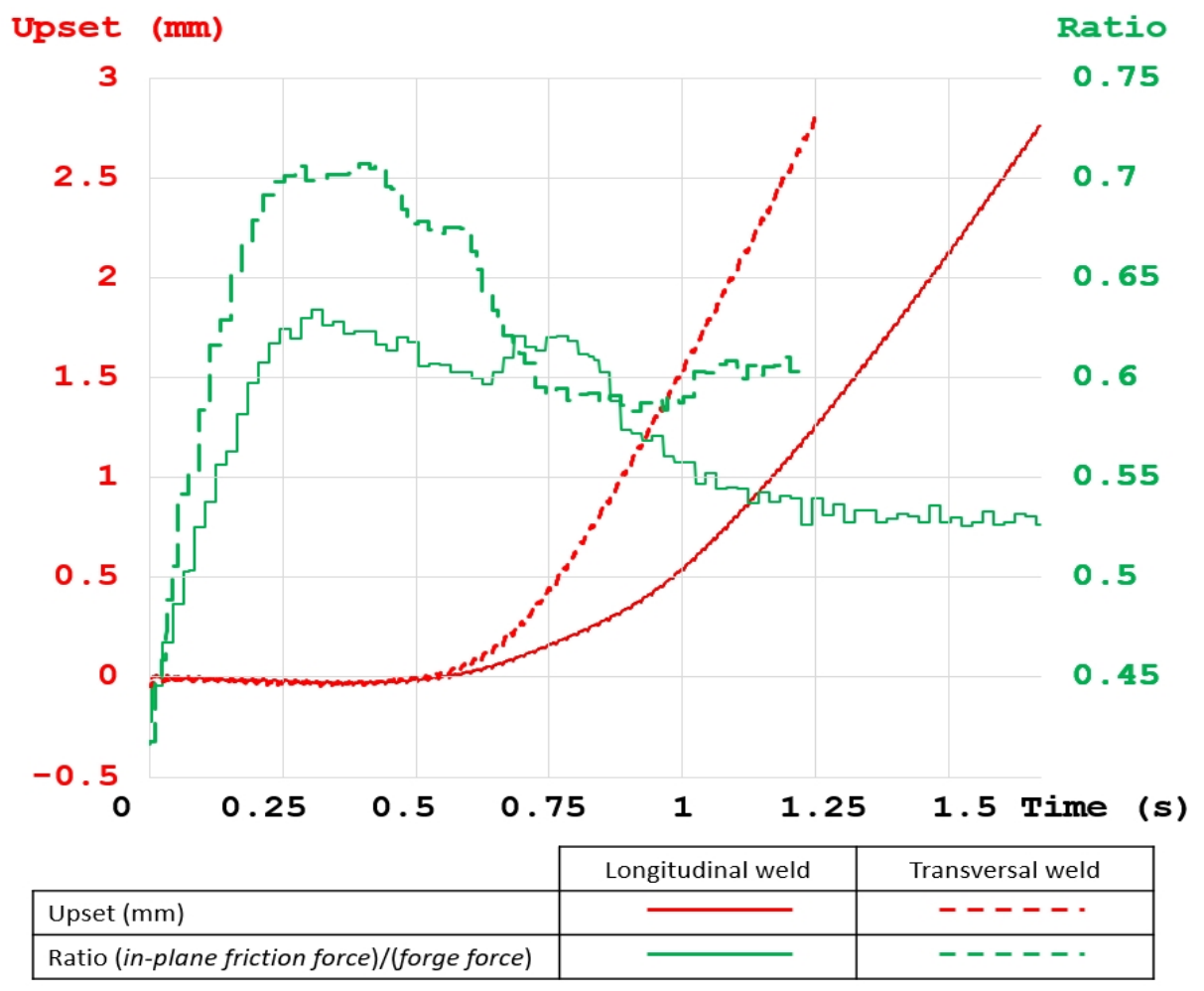

Figure 8. Comparison of upset and peak in-plane force for a longitudinal weld and a transversal weld

Several observations were made.

The variations of power input and overall energy input are very low compared to very wide process window weldability for LFW on Ti-6Al-4V.

Longitudinal welds show lower variations in power input, energy input and friction duration than transversal welds.

The power input is higher for transversal welds. This is the sign of a higher in-plane load at the interface. Machine acquisitions confirm that the in-plane load is higher during both conditioning and equilibrium phases.

The friction duration is shorter for transversal welds. This is due to a faster upset speed. This higher speed is understood to be caused by a larger volume of molten material pushed out of the interface at each oscillation, because the long side of the coupon is perpendicular to oscillation direction. 
Machine acquisitions show that despite a higher power input the transversal welds require a lower overall energy input, thanks to the shorter friction time. Furthermore, during the equilibrium phase of a transversal weld, a higher in-plane load is used to plough and plush the material out of the weld. In other words, during this phase, the power of in-plane action used to push the material out of the weld is higher than in longitudinal welds, and this power is not converted into heat at the interface, but in mechanical pushing action and heat in the flash.

For both longitudinal and transversal welds, the variations in overall energy input are lower than the variations in friction duration, this is the most remarkable learning of this study. This leads to conclude that the upset length is an end criterion better than friction duration, as far as the heat input repeatability is concerned.

\section{$\underline{\text { IV. Conclusions }}$}

LFW on Ti-6Al-4V was investigated through several industrial aspects. The process control accuracy of LFW machine was evaluated, showing performances far better than the strict requirements of a good weldability for Ti-6Al-4V. The high accuracy and repeatability of LFW machine allowed to evaluate the repeatability of upset speed behavior. The power input was measured and proven to be very repeatable, although dependent on weld configuration longitudinal or transversal. Considering the high level of automation in the process control, the good repeatability achieved by LFW machines and the high repeatability of process behavior, it is relevant to use a weld quality control method based on the machine recordings and in particular the measurement of power input. Such In-Process Quality Control strategy would enable to reduce production costs by avoiding or reducing some other non-destructive testing on the welds.

\section{$\underline{\text { References }}$}

[1]. A. Vairis and M. Frost, Modelling the linear friction welding of titanium blocks (Materials Science and Engineering, 2000), 8-17

[2].A. Vairis and M. Frost, On the extrusion stage of linear friction welding of Ti-6Al-4V (Materials Science and Engineering, 1999), 477-484

[3]. R. Turner et al., Linear friction welding of Ti-6Al-4V: Modelling and validation (Acta Materalia 59, 2011), 3792-3803

[4]. P. Wanjara and M. Jahazi, Linear Friction Welding of Ti-6Al-4V: Processing, Microstructure, and Mechanical-Property Inter-Relationships (Metallurgical and Materials transactions, 2005)

[5]. J. Romero et al., Effect of the forging pressure on the microstructure and residual stress development in Ti-6Al-4V linear friction welds (Acta Materalia 57, 2009), 5582-5592 